\title{
Effect of a Serious Game Jestimule in Emotion Recognition of Moroccan Autistic Children
}

\author{
Mammad Khaoula \\ Equip of Clinical and Cognitive Neuroscience and Nutritional Health, Department of Biology, Faculty \\ of Science, PO Box I 33 Kenitra, Morocco. \\ Khaoula.mammad@gmail.com \\ Ahami Ahmed Omar Touhami \\ Equip of Clinical and Cognitive Neuroscience and Nutritional Health, Department of Biology, Faculty \\ of Science, PO Box 133 Kenitra, Morocco. \\ ahami_40@yahoo.fr
}

\begin{abstract}
Human beings can express their emotions through various ways, such as facial expressions, bodily expressions, prosody, or language. Autism Spectrum Disorder (ASD) is a life-long neuro developmental disorder, characterized by varying levels of deficit in social and communication skills. A "serious game" called "JeStimule" has been developed to improve on the facial emotion recognition skills of children with autism. As many as 17 autistic children with distinctive characteristics were recruited for this cross-sectional study. The level of language comprehension and academic learning is slightly heterogeneous. The participants are predominantly boys, with an average age of II.23. Our finding shows that children have gradual ease in recognizing the following emotions: Happiness, surprise, sadness, anger, pain and fear. However, they find it challenging to recognize the remaining three emotions, namely neutral, funny face, and disgust. JeStimule is an effective educational game for children with autism that could improve their skills in recognizing others' emotion. However, further research needs to be carried out to test the game in the context of Moroccan children. Autism recognition of emotions is a cognitive remediation area of great interest to this population.
\end{abstract}

Keywords: Emotion recognition, game, Jestimule, autism, children.

Received 24 December 20I7/Accepted 30 March 2018 (C) JEHCP All rights reserved

\section{Introduction}

Autism spectrum disorder (ASD) is a complex neurodevelopmental disorder characterized by difficulties in social and interpersonal communication, combined with stereotyped and repetitive behaviors and interests (APA, 2013). According to the Fifth Edition of the Diagnostic and Statistical Manual of Mental Disorders (DSM-5), repetitive behavioursoftenco-occur with sensory abnormalities and language development delay or 
absence. Although ASDs are heterogeneous in etiology and symptoms, a common central feature is that deficit in social behaviorremains to be unrelated to cognitive dysfunction. Part of the deficit includes social impairments, such as the inability to initiate social interactions or develop relationships, lack of social or emotional reciprocity and lack of interest in others' feelings (Lord et al., 2000; Bauminger et al., 2003)

The earliest evidence of social impairments in ASD is new-borns' disrupted selective attention, evident through their lack of innate preference for human voice and face over other sounds and visual stimuli (Volkmar et al., 1990). Infants with ASD demonstrate impaired joint attention (Mundy et al., 1990), which is the ability to alert another person of an object through share gaze. This function mainly involves the cortical brain region. Hence, cortical dysfunction might lead to cognitive dysfunction in general, as well as specific impairments in social cognition and sensory integration. It remains unknown why social cognition is impaired explicitly in subjects with otherwise normal cognition. Meanwhile, brain areas that compriseof the "social brain", particularly medial prefrontal cortex (mPFC), amygdala, anterior insula, anterior cingulate cortex, inferior frontal gyrus and superior temporal sulcus, mediate these functions. Furthermore, a meta-analysis by DiMartino et al. (2009) found that emotion recognition impairments in ASD most notably impact the hypoactivation of amygdala and fusiform face area in the temporal lobe. Dalton et al. (2005) suggested that irregular and inconsistent patterns of fusiform gyrus activation, especially the right fusiform gyrus, contribute to face processing impairments in autistic people.

Additionally, the role of amygdala in social behaviour includes the processing of emotional reactions, visual social stimuli and social emotion cue from faces.lt has a vital role in recognizing facial emotion, as well as mediates eye gaze (Fried et al., 1997). Subjects with complete amygdala lesions, like those with ASD, show impaired eye contact (Spezio et al., 2007). Additionally, impaired ability in recognizing social cue from faces was also found among high-functioning subjects with ASD, namely those with focal bilateral amygdala lesion (Adolphs et al., 200I).

Social cognition is one of the components involved in regulating interactions. This component appears to be disrupted in people with ASD. Thus, several authors have 
highlighted difficulties in recognizing and understanding facial/gestural emotions (Da Fonseca et al., 2009), poor emotional vocabulary (Begeer, 2008), lack of verbal interaction and cognitive deficit, as some of the challenges faced by people with ASD. Specific care to improve social cognition in people with ASD could have a positive impact on their social interactions.

Emotion regulation is crucial for optimal functioning and long-term adaptive outcomes because they facilitate the stimulation of appropriate responses and coping mechanism in social interactions (Gross, 1998; Gross, 2007; Silk, Steinberg \&Morris, 2003). Recent studies show that individuals with ASD have difficulties regulating their emotions and suffer from serious emotional disturbances (Laurent \& Rubin, 2004; Mazefsky, Borue, Day \& Minshew, 20I4; Mazefsky et al., 20I3; Samson, Hardan, Podell, Phillips \& Gross, 20I4; Samson, Huber \& Gross, 2012; Samson, Phillips et al., 20I4). They experience more difficulty in generating cognitive reappraisal strategies compared to the average children. This is potentially due to their decreased ability to identify and describe emotions, as well as lack of insight into complex emotional processes (Capps, Yirmiya, \& Sigman, 1992; Losh \& Capps, 2006). Moreover, few studies suggest that individuals with ASD experience less amusement in response to humorous material compared to the typical people. They practice more maladaptive/ idiosyncratic strategies compared to emotion regulation strategies (Jahromi, Meek \& Ober-Reynolds, 20I2; Konstantareas \& Stewart, 2006; Mazefsky et al., 20I4; Rieffe et al., 20I I; Samson et al., 2012; Samson, 2013).

Digital tools have not always been considered favorable. Nevertheless, numerous changes in points of view seem to be influenced by digital tools. It is now possible to elicit technology users' interest by emphasizing on learning techniques and socialization between users of the same tools (Baranowski et al., 2003; Ito et al., 2008; Lenhart et al., 2008). Virtual environment has attracted many interest in the case of stimulation and cognitive remediation in children. These digital tools allow the stimulation of cognitive process, particularly regarding children's attention and executive functioning (Virole \& Radillo, 20I0). 
The absence of the regular pedagogical supervision for children could potentially capture their attention. In other words, learning through games introduces a novel way of teaching values and actions to children. Hence, it allows children with autism or Pervasive Developmental Disorder (PDD) to learn facial emotion recognition through their avatars, while taking into consideration various situational context (Serret et al., 20I2). Outside the medical setting, education practitioners' interest in using it to prevent school drop-out gradually increases (Wastiau, Kearney \& Van den Berghe, 2009). In recent years, many programs have been created to improve the social skills of people with ASD. Many studies on the use of these programs show promising results. However, most of these programs are limited to people with high-level autism or Asperger's syndrome (Golan et al., 2010). Our study is the first to apply "JeStiMulE" on autistic children in Morocco. The aim of this studyis to explore the influence of "JeStiMulE"in improving the facial emotion recognition skill of children with autism.

\section{Method}

A total of 17 autistic children with distinctive characteristics were recruited for this crosssectional study. The participants' age ranged between 5 to 14 years old. Their level of language comprehension and academic learning is slightly heterogeneous. We used the Childhood Autism Rating Scale (CARS) as a diagnostic tool under the supervision of our unit. Participants were given a JeStiMulE learning task one hour a day for three months. We conducted the supervision of these tasks along with an educator.

JeStiMulE, a prototype of a "serious game" developed as part of a national collaborative project, is an interactive and multi-sensory stimulation game for children and adolescents with Pervasive Developmental Disorder-Not Otherwise Specified (PDD-NOS). It aims to introduce children or adolescents with PDD to reciprocal social interactions in a virtual reality. This includes learning to recognize facial emotion, emotional gesture and social situations.

There are two phases to this two-dimensional game. Firstly, participants are subjected to a series of mini-games that gradually increases in complexity. It aims to train their skills in 
recognizing emotion and emotional gestures on the avatars. Initially, participants are introduced to the basic emotions (joy, anger, disgust, sadness, surprise, and fear) (Eckman, 1999) as well as pain (Serret et al., 2012). Next, neutral expression and gestures were presented to represent the absence of emotion on a face. Lastly, "funny face" was shown in this learning phase to visually show autistic children that face mimicry may not automatically correspond to an emotion (Serret et al., 2012).

The second phase of the game is the training phase. It is conducted through a virtual simulation in three dimensions. It consists of three game modules. The gaming platform is virtual and represents the district of a city with five playgrounds: restaurant, theatre, shop, kindergarten and city square. The player is free to move wherever he/she wants in the city. Their goal is to recognize or anticipate emotions of the game avatars in different social contexts.

\section{Analysis}

The statistical analyses were conducted using Microsoft Office Excel and Statistica software. We used non-parametric methods, namely descriptive statistic and Spearman Rank Order Correlations.

\section{Result}

Descriptive statistic

Our sample contains $12 \%$ girls and $88 \%$ boys. Among these children, $29 \%$ of them could read while $71 \%$ are not able to read. Additionally, more than half are able to communicate verbally (59\%), whilst the rest can only do so non-verbally (4I\%). The children are divided into three categories according to their type of autism: 35\% LFA, I2\% MFA and 53\% HFA. 
Journal of Educational, Health and Community Psychology

Vol 7, No I, 2018 E-ISSN 2460-8467 Mammad Khaoula, Ahmed Ahami

Table I

Distribution of sex/ability to read/ability to speak/ type of autism

\begin{tabular}{lcc}
\hline Sex & $\mathrm{F}$ & $12 \%$ \\
\cline { 2 - 3 } & $\mathrm{M}$ & $88 \%$ \\
\hline Ability to Read & Yes & $29 \%$ \\
& No & $71 \%$ \\
Ability to Speak & Yes & $59 \%$ \\
& No & $41 \%$ \\
Type of autism & LFA & $35 \%$ \\
& MFA & $12 \%$ \\
(LFA: Low-Functioning Autism; MFA: Moderate-Functioning Autism; HFA: High-Functioning Autism)
\end{tabular}

The serious game JeStiMulE:

Evaluation of social cognition: Options I

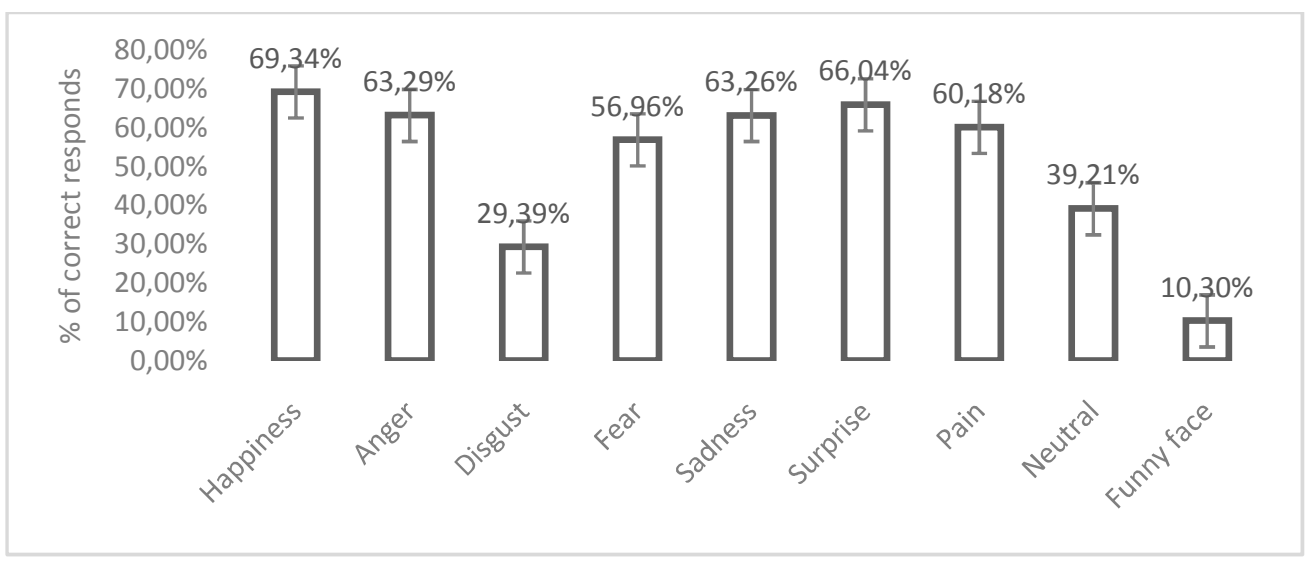

Figure I. Learning Phase OptionOne

The first part of the game (Option I) reveals that, based on the children's responses, the emotions that were most easily recognized accurately in descending order: Happiness = 69.34\%; Surprise $=66.04 \%$; Anger $=63.29 \%$; Sadness $=63.26 \%$; Pain $=60.18 \%$; Fear $=$ $56.96 \% ;$ Neutral $=39.21 \%$; Disgust $=29.39 \% ;$ Funny face $=10.30 \%$. 
Journal of Educational, Health and Community Psychology

Vol 7, No I, 2018 E-ISSN 2460-8467 Mammad Khaoula, Ahmed Ahami

Evaluation of social cognition: Option two

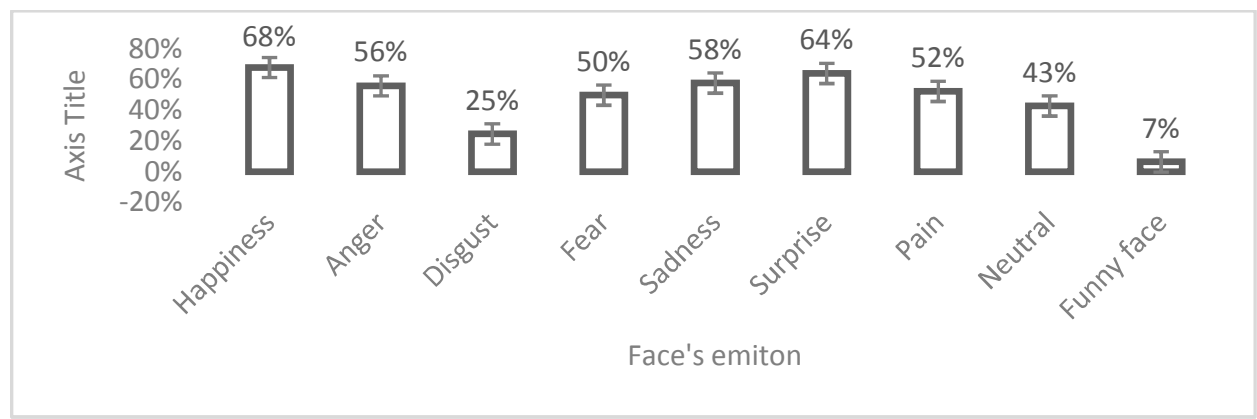

Figure 2. Learning phase option two

The second part of the game shows that, based on the children's responses, the emotions that were most easily recognized accurately in descending order: Happiness $=$ $68 \%$; Surprise $=64 \% ;$ Sadness $=58 \% ;$ Anger $=56 \% ;$ Pain $=52 \% ;$ Fear $=50 \%$; Neutral $=$ $43 \%$; Disgust $=25 \%$; Funny face $=7 \%$.

Evaluation of social cognition: Level I

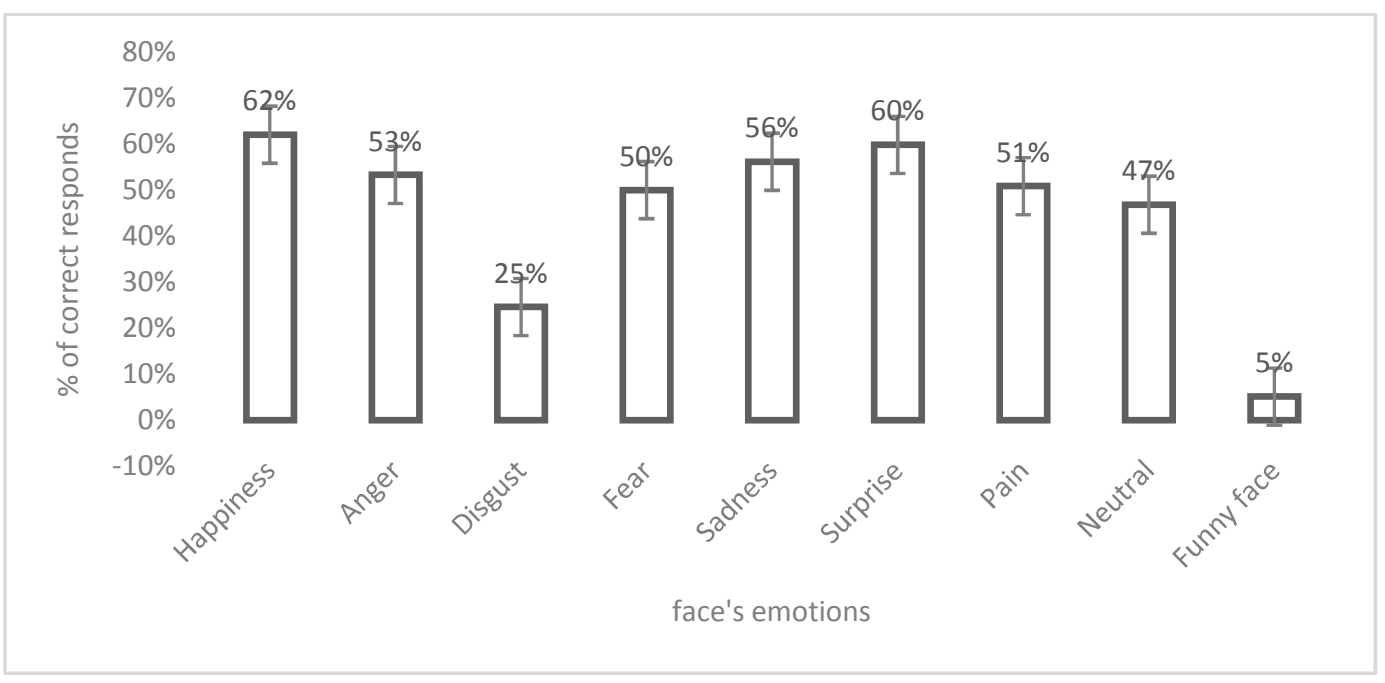

Figure3.The mean percentage of emotion, Level : I 
Journal of Educational, Health and Community Psychology

Vol 7, No I, 2018 E-ISSN 2460-8467

Mammad Khaoula, Ahmed Ahami

The third part of the game reveals that, in level I, most children correctly responded to these emotions: Happiness $=62 \%$; Surprise $=60 \%$; Sadness $=56 \%$; Anger $=53 \%$; Pain $=$ $5 \mathrm{I} \%$; Fear $=50 \% ;$ Neutral $=47 \%$; Disgust $=25 \%$; Funny face $=5 \%$.

Evaluation of social cognition: Level 2

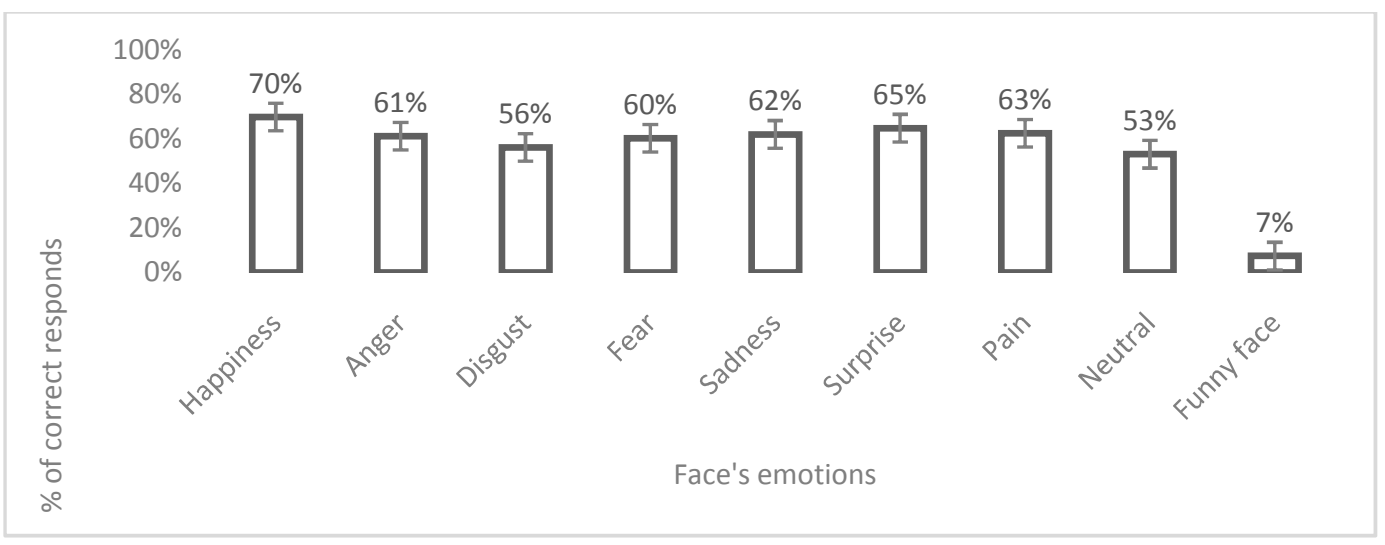

Figure 4. Learning phase: Level 2

The fourth part of the game (level 2) shows that, based on the children's answers, they easily recognized these emotions: Joy $=70 \%$; Surprise $=65 \%$; Sadness $=52 \%$; Anger $=61 \%$; Pain $=63 \%$; Fear $=60 \%$; Neutral $=53 \%$; Disgust $=56 \%$; Grimace $=7 \%$.

Evaluation of social cognition: Level 3

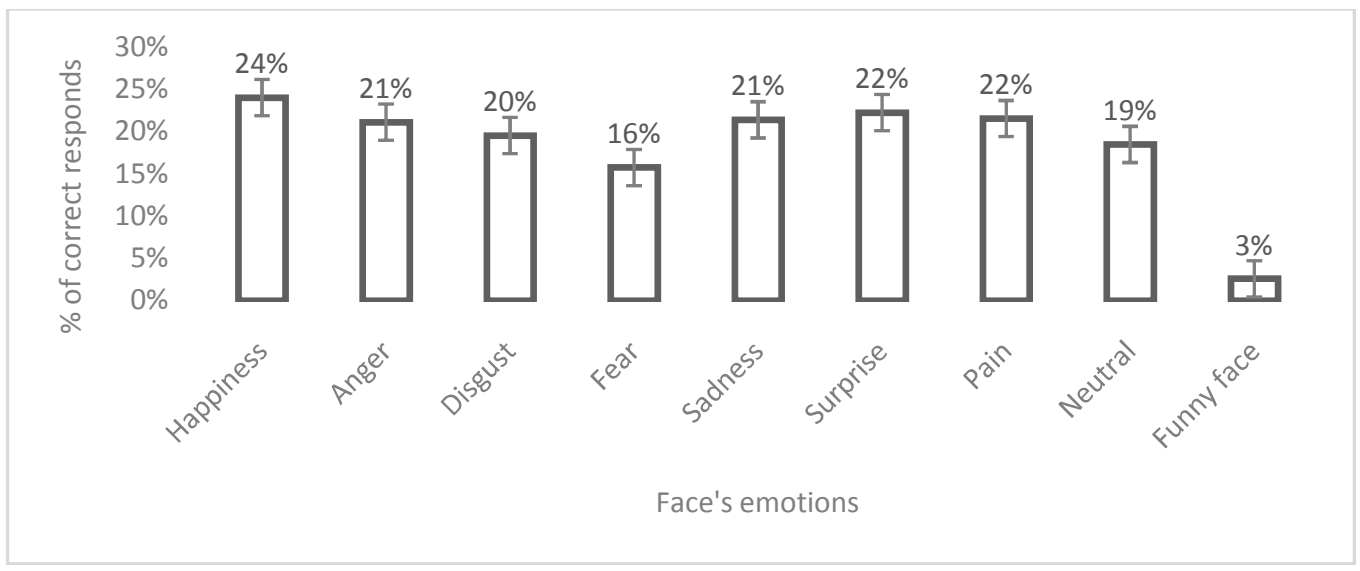

Figure5. Learning phase: Level 3 
Journal of Educational, Health and Community Psychology

Vol 7, No I, 2018 E-ISSN 2460-8467 Mammad Khaoula, Ahmed Ahami

The fifth part of the game (level 3), reveals that the children's answers in descending order: Joy $=24 \%$; Surprise $=22 \%$; Sadness $=52 \%$; Anger $=21 \%$; Pain $=22 \%$; Fear $=16 \%$; Neutral $=19 \%$; Disgust $=20 \%$; Grimace $=3 \%$.

Evaluation of social cognition:Level:I, 2 \& 3

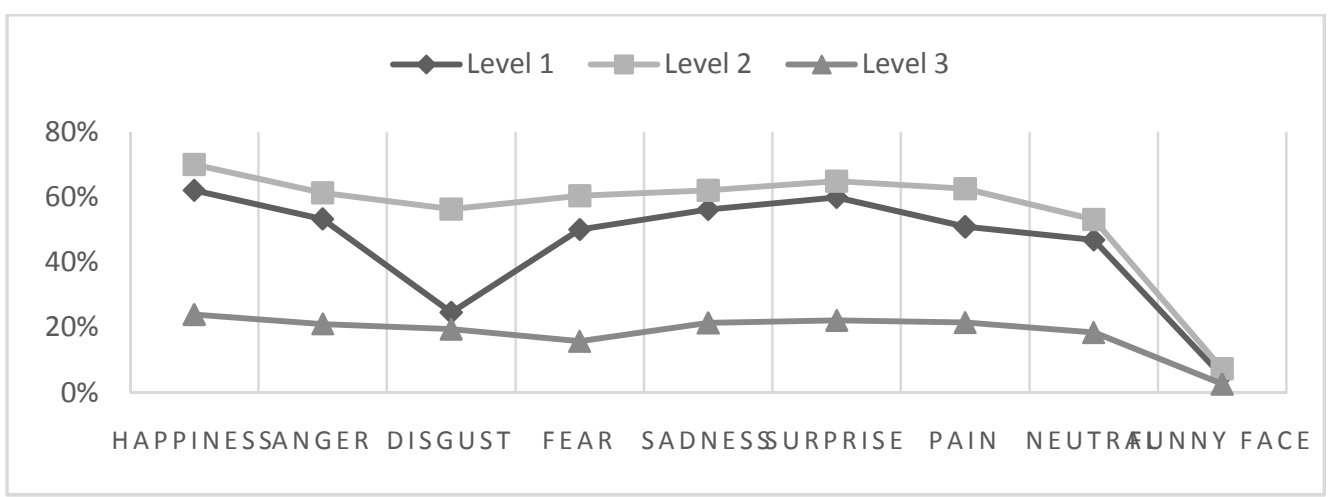

Figure 6.Comparison of the results of the 3 levels

Comparison between all three levels shows that knowledge on emotion at level two is better compared to results from level one and three.

Correlation between different levels of learning phase with sex, age, ability to read\& type of autism: Learning phase: Option I

Table 2

Learning Phase Part I Correlation: Option I

Happiness Anger Disgust Fear Sadness Surprise Pain Neutral $\begin{gathered}\text { Funny } \\ \text { Face }\end{gathered}$

\begin{tabular}{llllllllll}
\hline Sex & $r=-0.06$ & $r=-0.06$ & $r=0.00$ & $r=0.01$ & $r=-0.01$ & $r=0.00$ & $r=-0.04$ & $r=0.06$ & $r=-0.13$ \\
Age & $r=-0.62$ & $r=-0.62$ & $r=-0.58$ & $r=-0.57$ & $r=-0.54$ & $r=-0.57$ & $r=-0.73$ & $r=-0.62$ & $r=-0.63$ \\
$\begin{array}{l}\text { Ability to } \\
\text { Read }\end{array}$ & $r=-0.50$ & $r=-0.50$ & $r=-0.35$ & $r=-0.53$ & $r=-0.46$ & $r=-0.49$ & $r=-0.50$ & $r=-0.40$ & $r=-0.45$ \\
$\begin{array}{l}\text { Type of } \\
\text { Autism }\end{array}$ & $r=0.89$ & $r=0.89$ & $r=0.92$ & $r=0.87$ & $r=0.88$ & $r=0.87$ & $r=0.88$ & $r=0.92$ & $r=0.79$ \\
V OU NV & $r=0.87$ & $r=0.88$ & $r=0.84$ & $r=0.87$ & $r=0.87$ & $r=0.87$ & $r=0.87$ & $r=0.85$ & $r=0.78$ \\
\hline
\end{tabular}

Spearman Rank Order Correlations, MD pair wise deleted Marked correlations are significant at $P$ $<.05$ 
Journal of Educational, Health and Community Psychology

Vol 7, No I, 2018 E-ISSN 2460-8467 Mammad Khaoula, Ahmed Ahami

Table 2 shows that there is a negative correlation between children's responses regarding emotions in Option I with age and ability to read. Meanwhile, a positive correlation with type of autism and ability to speak was found. No correlation was found between emotion recognition and sex.

Table 3

Learning Phase Part 2 Correlation: Option2

\begin{tabular}{lllllllllll}
\hline & Happiness & Anger & Disgust & Fear & Sadness & Surprise & Pain & Neutral & $\begin{array}{c}\text { Funny } \\
\text { Face }\end{array}$ \\
& & & & & & & & & \\
\hline Sex & $r=-0.15$ & $r=-0.10$ & $r=-0.06$ & $r=-0.11$ & $r=-0.11$ & $r=-0.15$ & $r=-0.10$ & $r=-0.10$ & $r=-0.08$ \\
Age & $r=-0.62$ & $r=-0.58$ & $r=-0.62$ & $r=-0.61$ & $r=-0.53$ & $r=-0.59$ & $r=-0.60$ & $r=-0.70$ & $r=-0.58$ \\
Ability to & $r=-0.45$ & $r=-0.45$ & $r=-0.31$ & $r=-0.39$ & $r=-0.43$ & $r=-0.46$ & $r=-0.44$ & $r=-0.49$ & $r=-0.22$ \\
Read & & & & & & & & & \\
Type of & $r=0.92$ & $r=0.91$ & $r=0.92$ & $r=0.92$ & $r=0.89$ & $r=0.92$ & $r=0.92$ & $r=0.92$ & $r=0.79$ \\
Autism & & & & & & \\
V OU NV & $r=0.87$ & $r=0.87$ & $r=0.85$ & $r=0.87$ & $r=0.87$ & $r=0.87$ & $r=0.87$ & $r=0.87$ & $r=0.75$ \\
\hline
\end{tabular}

Spearman Rank Order Correlations, MD pairwise deleted Marked correlations are significant at $p<.05000$

Table 3 depicts the correlation result between emotion recognition in learning phase part 2 (option 2) with sex, age, ability to read, type of autism and ability to speak. Based on table 3 there is a negative correlation between children's responses to emotions in Option 2 with age and ability to read. Additionally, we also found a positive correlation with type of autism and ability to speak. However, no correlation was found between emotion recognition skill and sex. 
Journal of Educational, Health and Community Psychology

Vol 7, No I, 2018 E-ISSN 2460-8467 Mammad Khaoula, Ahmed Ahami

Table 4

Learning Phase Part 3 Correlation: Level I

\begin{tabular}{|c|c|c|c|c|c|c|c|c|c|}
\hline & Happiness & Anger & Disgust & Fear & Sadness & Surprise & Pain & Neutral & $\begin{array}{c}\text { Funny } \\
\text { Face }\end{array}$ \\
\hline Sex & 13 & $\begin{array}{l}r=- \\
0.10\end{array}$ & 0.06 & 10 & 0 & $r=-0.13$ & $\begin{array}{l}r=- \\
0.10\end{array}$ & & $r=-0.11$ \\
\hline Age & $r=-0.64$ & $\begin{array}{l}r=- \\
0.63\end{array}$ & $r=-0.62$ & $r=-0.71$ & $r=-0.64$ & $r=-0.69$ & $\begin{array}{l}r=- \\
0.63\end{array}$ & $r=-0.64$ & $r=-0.65$ \\
\hline $\begin{array}{l}\text { Ability to } \\
\text { Read }\end{array}$ & $r=-0.47$ & $\begin{array}{l}r=- \\
0.47\end{array}$ & $r=-0.40$ & $r=-0.45$ & $r=-0.42$ & $r=-0.47$ & $\begin{array}{l}r=- \\
0.47\end{array}$ & $r=-0.47$ & $r=-0.38$ \\
\hline $\begin{array}{l}\text { Type of } \\
\text { Autism }\end{array}$ & $r=0.92$ & $r=0.90$ & $r=0.92$ & $r=0.92$ & $r=0.92$ & $r=0.92$ & $r=0.92$ & $r=0.92$ & $r=0.92$ \\
\hline V OU NV & $r=0.87$ & $r=0.87$ & $r=0.85$ & $r=0.88$ & $r=0.85$ & $r=0.87$ & $r=0.87$ & $r=0.88$ & $r=0.878$ \\
\hline
\end{tabular}

Spearman Rank Order Correlations (Statistic Jestimule) MD pairwise deleted Marked correlations are significant at $p<.05000$

Table 4 shows that there is a negative correlation between children's responses regarding Level I emotions with age. Furthermore, there is also a positive correlation with the type of autism and ability to speak. No correlation between emotion recognition with sex and ability to read was found.

Table 5

Learning Phase Part 4 Correlation: Level 2

Happiness Anger Disgust Fear Sadness Surprise Pain Neutral Funny

\begin{tabular}{|c|c|c|c|c|c|c|c|c|c|}
\hline Sex & $r=-0.10$ & $\begin{array}{l}r=- \\
0.18\end{array}$ & $r=-0.21$ & $r=-0.12$ & $r=-0.13$ & $r=-0.15$ & $r=-0.15$ & $r=-0.21$ & $r=-0.06$ \\
\hline Age & $r=-0.67$ & $\begin{array}{l}r=- \\
0.53\end{array}$ & $r=-0.45$ & $r=-0.63$ & $r=-0.48$ & $r=-0.55$ & $r=-0.56$ & $r=-0.52$ & $r=-0.69$ \\
\hline $\begin{array}{l}\text { Ability to } \\
\text { Read }\end{array}$ & $r=-0.50$ & $\begin{array}{l}r=- \\
0.36\end{array}$ & $r=-0.28$ & $r=-0.54$ & $r=-0.40$ & $r=-0.50$ & $r=-0.36$ & $r=-0.30$ & $r=-0.43$ \\
\hline $\begin{array}{l}\text { Type of } \\
\text { Autism }\end{array}$ & $r=0.92$ & $r=0.92$ & $r=0.92$ & $r=0.87$ & $r=0.92$ & $r=0.93$ & $r=0.91$ & $r=0.92$ & $r=0.92$ \\
\hline V OU NV & $r=0.87$ & $r=0.87$ & $r=0.85$ & $r=0.91$ & $r=0.87$ & $r=0.87$ & $r=0.87$ & $r=0.84$ & $r=0.88$ \\
\hline
\end{tabular}

Spearman Rank Order Correlations (Statistic Je stimule) MD pairwise deleted Marked correlations are significant at $\mathrm{p}<.05$

Table 5 shows that there is a negative correlation between children's responses to Level 2 emotions with age and ability to read. Meanwhile, a positive correlation was found with type 
Journal of Educational, Health and Community Psychology

Vol 7, No I, 2018 E-ISSN 2460-8467 Mammad Khaoula, Ahmed Ahami

of autism and ability to speak. No correlation was found between emotion recognition and sex.

Table 6

Learning Phase Part 5 Correlation: Level 3

Happiness Anger Disgust Fear Sadness Surprise Pain Neutral Funny

$\begin{array}{llllllllll}\text { Sex } & r=-0.095 & r=-0.17 & r=-0.21 & r=-0.17 & r=-0.13 & r=-0.15 & r=-0.15 & r=-0.2 & r=-0.07 \\ \text { Age } & r=-0.67 & r=-0.52 & r=-0.45 & r=-0.65 & r=-0.48 & r=-0.55 & r=-0.55 & r=-0.52 & r=-0.68 \\ \begin{array}{l}\text { Ability to } \\ \text { Read }\end{array} & r=-0.50 & r=-0.36 & r=-0.28 & r=-0.52 & r=-0.40 & r=-0.49 & r=-0.36 & r=-0.30 & r=-0.43 \\ \begin{array}{l}\text { Type of } \\ \text { Autism }\end{array} & r=0.92 & r=0.92 & r=0.92 & r=0.58 & r=0.92 & r=0.92 & r=0.91 & r=0.92 & r=0.92 \\ \text { V OU NV } & r=0.87 & r=0.87 & r=0.85 & r=0.67 & r=0.87 & r=0.87 & r=0.87 & r=0.8 & r=0.88\end{array}$

Spearman Rank Order Correlations, MD pairwise deleted Marked correlations are significant at $p<, 05$

Table 6 shows that there is a negative correlation between children's responses to Level 3 emotions with age and ability to read. Additionally, there is also a positive correlation with the type of autism and ability to speak. Similar to most of the other results, no correlation was found between emotion recognition and sex.

\section{Discussion}

The participants of this study are predominantly boys, with an average age of II.23. The large number of illiterate participants shows that children are not subjected to a welldefined educational program. The type of autism we chose contains all the distinct categories to see the effectiveness of this game on these children. Despite several conflicting findings, studies indicate that people with ASD have difficulties identifying emotions from facial expressions (Philipetal, 20I0). Furthermore, a study indicates that although individuals with ASD may have intact emotion-recognition abilities, as measured by controlled behavioral paradigm, there may be heterogeneity within groups of autistic children to recognize emotion. This could be due to deficits in the ability to tap into the neural mechanisms underlying emotion processing, an automatic process in individuals with typical development. Furthermore, another study has found that the early development of neurons 
and brain overgrowth is most notable during the age of two to four years old, particularly development of the frontal lobe, temporal lobe, and amygdala (Hazlett et al., 2005). There is current evidence of an increasing abnormal short-distance connectivity within these brain regions, but a lack of connectivity between regions mediating the integration and processing of social and emotional information (Kleinhans et al., 2008).

Our findings have revealed that children have gradual ease in recognizing the following emotions: Happiness, surprise, sadness, anger, pain, and fear. These emotions were illustrated through their avatars for the children. The fact that they were basic emotions also further facilitates the ease in which children could understand them. Most current studies show that both low and high-functioning children, adolescents and adults with ASD, are less able to recognize complex non-verbal emotion such as embarrassment and trustworthiness compared to the typical children their age (Dziobek et al., 2006). Also, other studies found that ASD children and adults with normal intelligence are both impaired in their ability to recognize basic emotions, such as sadness and happiness (Kuusikko et al.,2009). However, Grossman, et al(2000), found that ASD groups with varying levels of functioning can accurately recognize basic emotions at a comparable level to the age and IQ that matches the average children and adults.

On the other hand, children found it very challenging to recognize three facial emotions, namely neutral, funny face, and disgust. Several reasons could cause this problem. Firstly, confusion could be due to the lack of refinement and clarity of the drawing that portrays the emotion. Secondly, recognizing these types of complex emotion requires a high level of emotional intelligence and cognitive knowledge that are often absence in children with ASD. Hence, they find it difficult to distinguish negative emotions such as hypocrite and deception or identify funny face. Thirdly, children with ASD have impaired social cognition, which is the ability to acquire, process, store and use social input from the environment to decide on and take proper social actions (Colle et al., 2007). It also relates to the process of understanding others or one's thoughts, mental states and feelings ("theory of mind," or mentalization) (Fletcher et al., 1995). As a result, children with ASD often have impaired social information analysis and abnormal responses. One of the ways to help autistic children or adolescent in recognizing complex emotion, such as disgust, would be to add 
sensations of smell and taste (Figure I,2,3,4, \&5). A recent study reported that children and adolescents with ASD are characterized by a relatively decreased modulation of amygdala activation when they consciously decrease affective responses to pictures that elicit disgust (Danial\&Wood, 2013; Sukhodolsky et al., 2013). That study also found group differences in insula activation, potentially due to the use of more emotionally evocative disgust pictures compared to neutral faces (Pitskel et al., 20I4).

Further, we conclude that there is a change in the degrees of children's responses. We found that level 2 was better compared to level I and 3, which corresponds to the effect of gestures and the addition of words and idioms. Initially, players began the learning process through a facial emotion recognition game at Level I. Next, gestures were then introduced in level 2 to expand their knowledge on expression of emotion. Finally, in level 3, players learned to recognize emotions with emotional words and idiomatic expressions. This last level proved to be quite complicated for children to understand because both the words and idiomatic expressions, were delivered in French instead of their mother tongue (Arabic). Additionally, there was no language option in the game (Figure 6). Paradigms that closely resemble naturalistic settings (Rump et al., 2009) have often indicated deficits in emotion recognition in children with ASD. Evers et al. (2014) incorporated hybrid faces comprising of emotional face-half, where the upper or lower face region demonstrated happiness, anger, sadness or fear and the other half showing a neutral expression. Based on that study, no emotion-recognition deficit in children with high-functioning ASD was found. Nevertheless, other studies have found that, both children with ASD and typical developing children mainly focused on the eye and mouth areas when correctly recognising emotions, although it remains to be strongly emotion-dependent. The differences in the nature of facial stimuli and emotions presented across tasks are accounted for the variation in findings of emotion-recognition performance across the autistic group. Some studies suggest that cognitive ability influences levels of internalization and externalization of difficulties in children with ASD (Witwer \& Lecavalier, 2010; Maskey et al., 2013). Moreover, a study showed that JeStiMulE presents a suitable usability. Most participants were able to play and complete the training within the expected time, supporting the idea that JeStiMulE specificities, including sensory, cognitive and motivational dimensions, are adaptable to the 
Autism Spectrum Conditions (ASC) profile. Participants were also able to play and benefit from the training, as indicated by their improved performance on emotional recognition tasks. Hence, this study provides evidence for the potential use of JeStiMulE in ASC individuals with heterogeneous intellectual, verbal and academic levels. However, it focused on individuals with high-functioning autism, including autism spectrum (Serret et al., 20I4). Children with LFA had great difficulty answering and recognizing the corresponding emotions. According to the authors, it is possible that children with LFA had difficulty understanding the game instructions. Therefore, they could not fully benefit from the intervention (Hopkins et al., 20I I).

The child's responses may also be influenced by other factors, such as age. Based on the correlation found, age can influence emotion recognition skills in children. The younger the age, the better the emotion recognition skills in children. Meanwhile, correlation with type of autism shows that children with LFA had difficulty adapting with the game because the concept is too complicated for them. In contrary, children with HFA could perform the task much easily compared to children with LFA. Most virtual programs are only accessible for people with HFA or Asperger's syndrome (Golan et al., 20I0).

A correlation with "ability to speak" shows that autistic children who are able to communicate verbally, finds the game easier to understand than those who are not able to speak. Preschool children with ASD demonstrate an impaired ability to modify their emotions appropriately in response to others (Konstantareas \& Stewart, 2006).Additionally, Loveland (2005) found that there are deficits in the ability to regulate emotion in response to emotional stimuli, ranging from flat affect to responding to others' emotion. However, no correlation has been found with sex, indicating that gender does not influence emotion recognition skills (Table I,2,3,4 \& 5). 
Journal of Educational, Health and Community Psychology

Vol 7, No I, 2018 E-ISSN 2460-8467

Mammad Khaoula, Ahmed Ahami

\section{Conclusion}

This type of educational game for children with autism is effective and important for the child's profile. It improves emotion recognition skills to understand others' emotion. However, further development on the educational program and game performance are still needed to solidify its' impact on the child's performance. Hence, more research needs to be carried out to put in place specific educational games in the context of Moroccan children. Autism recognition of emotions is a cognitive remediation area of great interest to this population. 
Journal of Educational, Health and Community Psychology

Vol 7, No I, 2018 E-ISSN 2460-8467

Mammad Khaoula, Ahmed Ahami

\section{References}

Adolphs, R., Sears, L., \& Piven, J. (200I). Abnormal processing of social information from faces in autism. Journal Cognitive Neuroscience, 13, 232-240.

American Psychiatric Association. (2013). Diagnostic and statistical manual of mental disorders (DSM-V). New York: American Psychiatric Publishing.

Baranowski, T., Baranowski, J., Cullen, K.W., Marsh, T., Islam, N., Zakeri, I., \&de Moor, C. (2003), Squire's Quest! Dietary outcome evaluation of a multimedia game. American Journal of Preventive Medicine, 24(I), 52-6I.

Bauminger, N., Shulman, C. \& Agam, G. (2003), Peer interaction and loneliness in highfunctioning children with autism. J. Autism Dev. Disord. 33, 489-507.

Begeer, S., Koot, H.M., Rieffe, C., Meerum Terwogt M., \& Stegge H. (2008). Emotional competence in children with autism: Diagnostic criteria and empirical evidence. Developmental Review, 28, 342-69.

Capps, L., Yirmiya, N., \& Sigman, M. (1992). Understanding of simple and complex emotions in non-retarded children with autism. Journal of Child Psychology and Psychiatry, and Allied Disciplines, 33, II69-1182.

Colle, L., Baron-Cohen, S. \& Hill, J. (2007), Do children with autism have a theory of mind? A non-verbal test of autism vs. specific language impairment. J. Autism Dev. Disord. 37, 716-723.

Da Fonseca, D., Santos, A., Bastard-Rosset, D., Rondan, C., Poinso, F., \& Deruelle, C. (2009). Can children with autistic spectrum disorders extract emotions out of contextual cues?. Research in Autism Spectrum Disorders, 3(I), 50-56.

Dalton, K. M., Nacewicz, B. M., Johnstone, T., Schaefer, H. S., Gernsbacher, M. A., \& Goldsmith, H. H., et al. (2005). Gaze fixation and the neural circuitry of face processing in autism. Nature Neuroscience, 8, 519-526.

Danial, J. T., \& Wood, J. J. (20/3). Cognitive behavioral therapy for children with autism: Review and considerations for future research. Journal of Developmental and Behavioral Pediatrics, 34(9), 702-7I5.

Di Martino, A., Ross, K., Uddin, L. Q., Sklar, A. B., Castellanos, F. X., \& Milham, M. P. (2009). Functional brain correlates of social and nonsocial processes in autism spectrum disorders: an activation likelihood estimation meta-analysis. Biological Psychiatry, 65, 6374. 
Dziobek, I., Fleck, S., Kalbe, E., Rogers, K., Hassenstab, J., Brand, M., \& Convit, A. (2006). Introducing MASC: a movie for the assessment of social cognition. Journal of Autism and Developmental Disorders, 36, 623-636.

Ekman, P., (1999). Basic emotions. New York: Sussex U.K.: John Wiley and Sons, Ltd, p. 30I320.

Evers, K., Kerkhof, I., Steyaert, J., Noens, I., \& Wagemans, J. (2014). No differences in emotion recognition in children with autism spectrum disorder: evidence from hybrid faces. Autism Research and Treatment, 2, I-8.

Fletcher, P. C., Happé, F., Frith, U., Baker, S. C., Dolan, R. J., Frackowiak, R. S., \& Frith, C. D. (1995). Other minds in the brain: A functional imaging study of "theory of mind" in story comprehension. Cognition, 57(2), 109-128. http://dx.doi.org/10.1016/00100277(95)00692-R

Fried, I., MacDonald, K. A., \& Wilson, C. L. (1997). Single neuron activity in human hippocampus and amygdala during recognition of faces and objects. Neuron, 18, 753765.

Golan, O., Ashwin, E., Granader, Y., McClintock, S., Day, K., Leggett, V., \& Baron-Cohen, S. (20l0). Enhancing emotion recognition in children with autism spectrum conditions: an intervention using animated vehicles with real emotional faces. J. Autism Dev. Disord, 40(3), 269-279. doi: 10.1007/s 10803-009-0862-9

Gross, J.J. (1998). The emerging field of emotion regulation: An integrative review. Review of General Psychology, 2, 27I- 299.

Gross, J.J., \& Thompson, R.A. (2007). Emotion regulation: Conceptual foundations. In J.J. Gross (Ed.), Handbook of emotion regulation (pp. 3-24). New York, NY: Guilford Press.

Grossman, J. B., Klin, A., Carter, A. S., \&Volkmar, F. R. (2000). Verbal bias in recognition of facial emotions in children with Asperger syndrome. Journal of Child Psychology and Psychiatry, 4I, 369-379.

Hazlett, H. C., Poe, M., Gerig, G., Smith, R. G., Provenzale, J., \& Ross, A., et al. (2005). Magnetic resonance imaging and head circumference study of brain size in autism: birth through age 2 years. Archives of General Psychiatry, 62, 1366-1376.

Hopkins, I. M., Gower, M. W., Perez, T. A., Smith, D. S., Amthor, F. R., Wimsatt, F. C., \& Biasini, F. J. (20II). Avatar assistant: Improving social skills in students with an ASD through a computer-based intervention. Journal of Autism and Developmental Disorders, $4 I$, I543-I555. 
Journal of Educational, Health and Community Psychology

Vol 7, No I, 2018 E-ISSN 2460-8467 Mammad Khaoula, Ahmed Ahami

Ito, M., Horst, H., Boyd, D., Bittanti, M., Herr-Stephenson, B., Lange, P. G., ... \& Robinson, L. (2008). Living and learning with new media: Summary of findings from the digital youth project. Chicago, IL: MacArthur Foundation.

Jahromi, L.B., Meek, S.E., \& Ober-Reynolds, S. (20I2). Emotion regulation in the context of frustration in children with high functioning autism and their typical peers. Journal of Child Psychology and Psychiatry, 53, 1250-1258.

Kleinhans, N. M., Richards, T., Sterling, L., Stegbauer, K. C., Mahurin, R., Johnson, L. C., ...Aylward, E. (2008). Abnormal functional connectivity in autism spectrum disorders during face processing. Brain, I3 I (Pt), 4. doi: 10.1093/brain/awm334

Konstantareas, M. M., \& Stewart, K. (2006). Affect regulation and temperament in children with autism spectrum disorder. Journal of Autism and Developmental Disorders, 36, 143154.

Kuusikko, S., Haapsamo, H., Jansson-Verkasalo, E., Hurtig, T., Mattila, M. L., Ebeling, H., \&Moilanen, I. (2009). Emotion recognition in children and adolescents with autism spectrum disorders. Journal of Autism and Developmental Disorders, 39, 938-945.

Laurent, A.C., \& Rubin, E. (2004). Challenges in emotional regulation in Asperger's syndrome and high-functioning autism. Topics in Language Disorders, 24, 286-297.

Lenhart, A., Kahne, J., Middaugh, E., Rankin Macgill, A., Evans, C. \& Vitak, J. (2008). Teens, video games and civics (rapport de recherche). Pew Research Center's Internet \& American Life Project.

Lord, C., Risi, S., Lambrecht, L., Cook, E., Leventhal, B., DiLavore, P., Pickles, A., \& Rutter, M. (2000). The autism diagnostic observation schedule-generic: A standard measure of social and communication deficits associated with the spectrum of autism. Journal of Autism \& Developmental Disorders, 30, 205-223.

Losh, M., \& Capps, L. (2006). Understanding of emotional experience in autism: Insights from the personal accounts of high-functioning children with autism. Developmental Psychology, 42, 809-818.

Loveland, K. (2005). Social-emotional impairment and self-regulation in Autism spectrum disorders. In J. Nadel \& D. Muir (Eds.), Typical and impaired emotional development (pp. 365-382). Oxford: Oxford University Press.

Mazefsky, C. A., Herrington, J., Siegel, M., Scarpa, A., Maddox, B. B., Scahill, L., \& White, S.W. (20I3). The role of emotion regulation in autism spectrum disorder. Journal of the American Academy of Child and Adolescent Psychiatry, 52, 679-688. 
Mazefsky, C.A., Borue, Z., Day, T. N., \& Minshew, N. J. (20I4). Emotion regulation patterns in adolescents with high functioning autism spectrum disorder: comparison to typically developing adolescents and association with psychiatric symptoms. Autism Research, 7, 344-354.

Mundy, P., Sigman, M., \& Kasari, C. A. (1990). longitudinal study of joint attention and language development in autistic children. J. Autism Dev. Disord, 20, II5-I 28.

Philip R. C. M., Whalley H. C., Stanfield A. C., Sprengelmeyer R., Santos I. M., \& Young A. W. (20I0). Deficits in facial, body movement and vocal emotional processing in autism spectrum disorders. Psychol. Med. 40, 1919-1929.

Pitskel, N. B., Bolling, D. Z., Kaiser, M. D., Pelphrey, K. A., \& Crowley, M. J. (20I4). Neural systems for cognitive reappraisal in children and adolescents with autism spectrum disorder. Developmental Cognitive Neuroscience, 10, I I7-128.

Rump, K.M., Giovannelli, J. L., Minshew, N. J., \& Strauss, M. S. (2009). The development of emotion recognition in individuals with autism. Child Development, 80, I434-I447.

Samson, A.C. (2013). Humor (lessness) elucidated-sense of humor in individuals with Autism Spectrum Disorders: review and introduction. International Journal of Humour Research, 26, 393-409.

Samson, A.C., Hardan, A.Y., Podell, R.W., Phillips, J.M., \& Gross, J.J. (20|4). Emotion regulation in children and adolescents with autism spectrum disorder. Autism Research. Advance Online publication. doi:10.1002/aur. 1387.

Samson, A.C., Huber, O., \& Gross, J.J. (2012). Emotion regulation in Asperger's syndrome and High Functioning Autism. Emotion, 12, 659-665.

Samson, A.C., Phillips, J.M., Parker, K.J., Shah, S., Gross, J.J., \& Hardan, A.Y. (2014). Emotion dysregulation and the core features of autism spectrum disorder. Journal of Autism and Developmental Disorders. Advance Online publication. DOI 10.1007/s I0803-0I3-2022-5.

Serret, S., Hun, S., lakimova, G., Lozada, J., Anastassova, M., Askenazy, F. (2012). Présentation d'un "seriousgame »: "JeStiMulE » visant à améliorer la cognition sociale des personnes avec un trouble envahissant du développement. Le Bulletin scientifique de l'ARAPI, n³0 - Automne. p.18-22

Serret, S., Hun, S., lakimova, G., Lozada, J., Anastassova, M., Santos, A., Vesperini, S., \& Askénazy, F., (2014). Facing the challenge of teaching emotions to individuals with lowand high-functioning autism using a new serious game: A pilot study. Molecular Autism, $5,37$. 
Silk, J.S., Steinberg, L., \& Morris, A.S. (2003). Adolescents' emotion regulation in daily life: Links to depressive symptoms and problem behavior. Child Development, 74, 1869I880. doi: 10.1017/SI3524658| 1000063

Spezio, M. L., Huang, P. Y., Castelli, F., \& Adolphs, R. (2007). Amygdala Damage Impairs Eye Contact during Conversations with Real People. Journal of Neuroscience, 27, 39943997.

Sukhodolsky, D. G., Bloch, M. H., Panza, K. E., \& Reichow, B. (20I3). Cognitive-behavioral therapy for anxiety in children with high-functioning autism: A meta-analysis. Pediatrics, I32(5), el34I-el350.

Virole, B., \& Radillo, A. (20I0). Cyberpsychologie. Paris: Dunod

Volkmar, F. R. \& Mayes, L.C. (1990). Gaze behavior in autism. Dev. Psychopathol. 2, 6I-69.

Wastiau, P., Kearn ey, C., \& Van den Berghe, W. (2009). How are digital games used in schools. Main results of the study. Synthesis report. Brussels: European Schoolnet.

Witwer, A. N., \& Lecavalier, L. (2010). Validity of comorbid psychiatric disorders in children with autism spectrum disorders. Journal of Developmental and Physical Disabilities, 22, 367-380. 